\title{
Oxintomodulina e obesidade
}

\author{
Oxyntomodulin and obesity
}

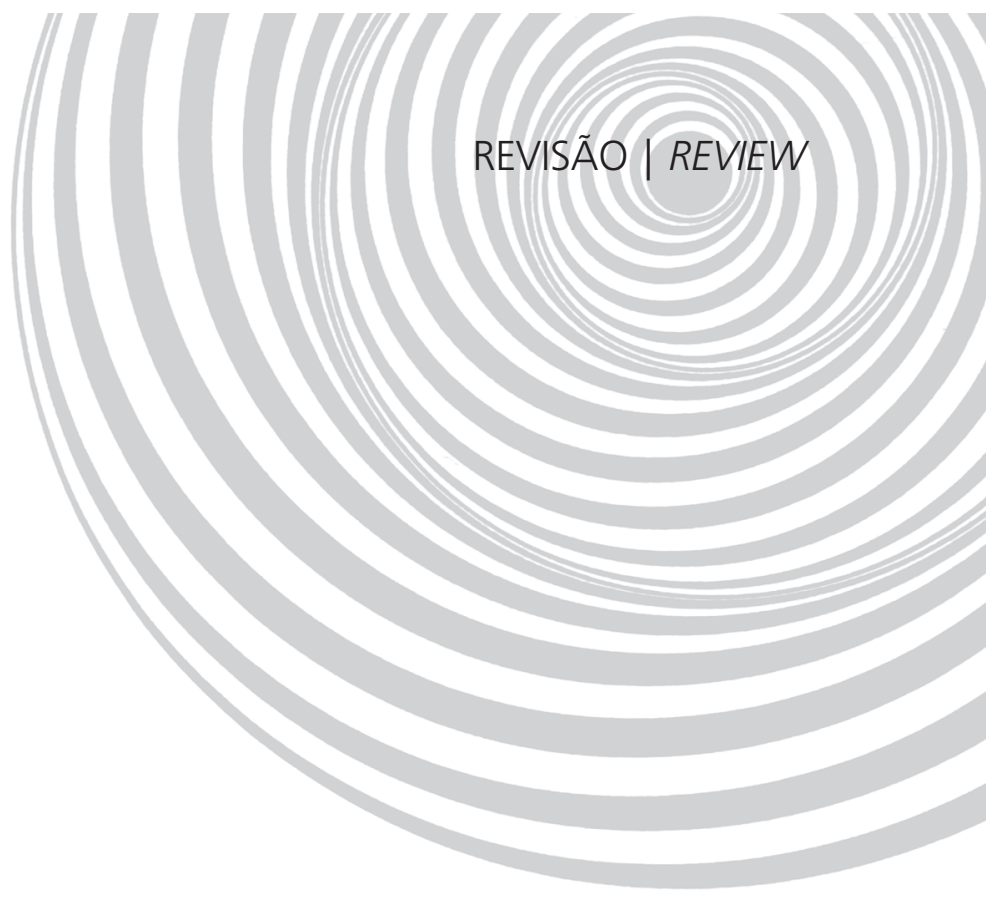

Gustavo Duarte PIMENTEL

João Felipe MOTA'

Lila Missae OYAMA²

RE S U M O

Desde o descobrimento da leptina, avanços consideráveis foram obtidos na caracterização dos mecanismos hipotalâmicos do controle da ingestão alimentar e, atualmente, a oxintomodulina é reconhecida como um regulador da homeostase energética. O presente artigo de revisão enfoca algumas das mais relevantes inter-relações do hormônio oxintomodulina com o apetite, a homeostase energética e aspectos de seu papel na bioquímica e fisiologia nutricional. A oxintomodulina é um peptídeo intestinal anorexígeno produzido pelas células $L$ do intestino. Recentes estudos têm demonstrado que em longo prazo a administração de oxintomodulina reduz a ingestão alimentar e o ganho de peso. Pesquisas em humanos têm verificado que o seu uso reduz o consumo energértico em $25 \%$. Portanto, a oxintomodulina representa uma potente terapia anti-obesidade. Entretanto, o mecanismo de ação da oxintomodulina ainda é desconhecido. Atuais evidências sugerem que tem ação via receptor do peptídeo semelhante ao glucagon 1. Além disso, a literatura mostra que, juntamente com a adoção de hábitos saudáveis e a mudança do estilo de vida, a oxintomodulina pode proporcionar menor avanço da obesidade.

Termos de indexação: Agentes anti-obesidade. Gastrointestinais. Hormônios. Obesidade. Peptídeos. Perda de peso.

A B S T R A C T

Since the discovery of leptin, great advances occurred in the characterization of hypothalamic mechanisms involved in the control of food intake and oxyntomodulin is currently recognized as a homeostasis energy regulator. This review discusses the most important interrelationships between the hormone oxyntomodulin and appetite, energy homeostasis and aspects of its role in nutritional biochemistry and physiology. Oxyntomodulin is an anorexigenic peptide produced by the $L$ cells of the small intestine. Recent studies have shown that long-term use of oxyntomodulin in rats leads to reduced food intake and weight gain. Studies in humans have demonstrated that its administration reduces food intake by $25 \%$. Therefore, oxyntomodulin represents a potent anti-obesity therapy. However, its mechanism of action is unknown. Current evidence suggests that it acts via the peptide receptor similar to glucagon 1. Moreover, the literature shows that together with the adoption of healthy habits and lifestyle changes, oxyntomodulin can reduce weight gain.

Indexing terms: Anti-obesity agents. Gastrointestinal. Hormones. Obesity. Peptides. Weight loss.

\footnotetext{
${ }^{1}$ Universidade Federal de São Paulo, Departamento de Fisiologia, Disciplina de Fisiologia da Nutrição. R. Botucatu, 862, Edifício de Ciências Biomédicas, $2^{\circ}$ andar, Vl. Clementino, 04023-062, São Paulo, SP, Brasil. Correspondência para/Correspondence to: G.D. PIMENTEL. E-mail: <gpimentel@unifesp.br>.

2 Universidade Federal de São Paulo, Departamento de Biociências, Campus Baixada Santista. Santos, SP, Brasil.
} 


\section{N T R O D U ÇÃ O}

A Organização Mundial de Saúde descreve a obesidade como uma das maiores ameaças à saúde humana. Estima-se que existam mais de 300 milhões de obesos e um bilhão de adultos com sobrepeso no mundo'. No Brasil, dados da Pesquisa de Orçamento Familiar (POF) ${ }^{2}$ revelaram que o excesso de peso afeta $41,1 \%$ dos homens e $40 \%$ das mulheres, visto que, neste grupo, a obesidade atingiu $8,9 \%$ dos homens e $13,1 \%$ das mulheres adultas.

Diante da elevada prevalência de obesidade, despertou interesse sobre o estudo da fisiologia e do controle da ingestão alimentar, na tentativa de desenvolver novas terapias contra esta epidemia ${ }^{3}$.

De acordo com a literatura, diversos fatores podem atuar na regulação da ingestão energética e contribuir para o ganho de peso. Dentre estes fatores, podem-se citar os neuronais, endócrinos, adipocitários e intestinais ${ }^{4}$. Na última década, após a descoberta da leptina, muitos estudos têm sido realizados em busca de entender os sinais reguladores do apetite e da homeostase energética. Diversos peptídeos sintetizados e secretados pelo trato gastrointestinal são conhecidos por regular o apetite ${ }^{5}$.

Dentre estes peptídeos pode-se citar a Oxintomodulina (OXM), que contém 37 aminoácidos e é sintetizada por meio do processamento pós-traducional do pró-glucagon nas células intestinais $L^{6,7}$. Em resposta à ingestão alimentar e proporcionalmente ao conteúdo energético, a OXM é secretada promovendo a saciedade. Dessa forma, por apresentar ações de regulação energética, a OXM tem sido considerada potente agente anti-obesidade ${ }^{7-11}$. Contudo, a escassez de pesquisas com OXM mostra necessidade de aprofundamento para melhor entendimento de seus efeitos metabólicos. Baseado nisso, este trabalho teve como objetivo realizar uma revisão bibliográfica, relacionando a OXM com a homeostase energética e seu papel no controle da ingestão alimentar, a fim de delinear as deficiências dos estudos, esclarecer e descrever seus reais ou possíveis efeitos sobre a alteração da composição corporal e a aplicabilidade em seres humanos.

\section{MÉTODOS}

O método para levantamento bibliográfico consistiu na pesquisa de periódicos, no período de 1979 a fevereiro/2009, nas seguintes bases de dados: Pubmed (National Library of Medicine), Capes (Coordenação de Aperfeiçoamento de Pessoal de Nível Superior, Brasil), SciELO (Scientific Electronic Library Online) e Bireme (Centro Latino-Americano e do Caribe de Informação em Ciências da Saúde, Brasil).

As seguintes palavras-chave foram cruzadas nos idiomas português, inglês e espanhol, de acordo com os descritores em Ciências da Saúde (DeCS): hormônios gastrointestinais, oxintomodulina, obesidade, regulação do apetite, composição corporal e metabolismo energético.

\section{Fisiologia da oxintomodulina}

A oxintomodulina foi descrita pela primeira vez no início dos anos $1980^{6,12}$ e a, partir desta década, as pesquisas demonstram o seu uso como potente alvo terapêutico contra a obesidade ${ }^{13,14}$. Os primeiros pesquisadores sobre o assunto observaram que a OXM é liberada pelas células enteroendócrinas em proporção à ingestão energética, em torno de 5 a 10 minutos após as refeições ${ }^{15,16}$.

A OXM é considerada membro da família do proglucagon derivado dos peptídeos intestinais. O gene produtor deste proglucagon, além de ser expresso nas células $L$ da porção distal do intestino, também é expresso no estômago, pâncreas e Sistema Nervoso Central (SNC) $)^{14}$. As enzimas convertases $\mathrm{C} 1$ e $\mathrm{C} 2$ clivam o proglucagon em diferentes produtos, dependendo dos sítios de síntese, sendo que cada órgão produz hormônios específicos ${ }^{17}$.

As células $L$ intestinais e o cérebro secretam principalmente a porção $\mathrm{N}$-terminal intacta 
do proglucagon, ou seja, a glicentina, conhecida como glucagon do intestino, juntamente com a OXM e os peptídeos semelhantes ao glucagon 1 e 2 (GLP-1 e 2). Já as células $\alpha$ pancreáticas secretam, principalmente, glucagon, peptídeo relacionado com a glicentina, e um grande peptídeo contendo as seqüências GLP-1 e 2, também conhecido como fragmento maior do proglucagon ${ }^{18}$.

A OXM apresenta uma seqüência de 37 aminoácidos, que começa em histidina e termina em alanina (His-Ser-Gln-Gly-Thr-Phe-Thr-Ser-AspTyr-Ser-Lys-Tyr-Leu-Asp-Ser-Arg-Arg-Ala-Gln-AspPhe-Val-Gln-Trp-Leu-Met-Asn-Thr-Lys-Arg-Asn-LysAsn-Asn-lle-Ala) ${ }^{19}$ e corresponde ao proglucagon que é localizado entre os aminoácidos 33 e $69^{20}$. As concentrações de OXM apresentam pico máximo por volta de 30 minutos no período pós-prandial, porém podem apresentar variações diurnas, independentemente da ingestão alimentar, com níveis mais altos à noite e baixos pela manhãa, ${ }^{1621}$. O tempo de meia-vida do hormônio é de, aproximadamente, 8,4 minutos (com variação de 2,0)22.

A compreensão da fisiologia da OXM é complicada pelas dificuldades em mensurar com precisão suas concentrações plasmáticas ${ }^{17}$. Em roedores, a concentração de OXM no trato gastrointestinal aumenta gradualmente entre o duodeno e o íleo, e depois disso diminui no ceco e no cólon ${ }^{23}$. Além da glicentina, a OXM também pode ser secretada juntamente com o peptídeo YY (PYY) 24 .

A imunoreatividade semelhante à OXM é o termo usado para descrever as concentrações plasmáticas mensuradas por radioimunoensaio. Com o envelhecimento e durante a liberação induzida pela alimentação, a OXM diminui em valores basais, resultando na redução e na absorção de carboidratos e também na baixa acidez gástrica ${ }^{16}$. Contudo, as concentrações de OXM estão aumentadas em certas condições, como anorexia, espru tropical e pós cirurgia de bypass jejuno ileal $\left.\right|^{23,25,26}$.

Segundo Verdich et al. ${ }^{27}$, a absorção ou mesmo a presença de alimento no trato gas- trointestinal contribui para a modulação do apetite e a regulação de energia. O intestino possui diferentes tipos de células secretoras de peptídeos que regulam o processo digestivo e atuam no Sistema Nervoso Central para a regulação da fome e da saciedade. A sinalização ocorre por meio dos nervos periféricos e seus receptores ${ }^{28}$.

Os hormônios intestinais, combinados a outros, podem estimular (grelina, orexina e NPY) ou inibir (OXM, PYY, obestatina, leptina, glicentina, colecistoquinina e GLP-1) a ingestão alimentar. Todos atuam nos centros hipotalâmicos, que são os grandes responsáveis pela sensação da fome, pelo estímulo à ingestão alimentar e pelo gasto energético ${ }^{29,30}$.

As regiões do cérebro contendo OXM ou glicentina incluem a medula oblongata (localizada na parte superior e grossa da espinha dorsal, portanto abaixo do cerebelo), bulbo olfatório, cerebelo, córtex e hipotálamo ${ }^{13}$. No Sistema Nervoso Central, o hipotálamo desempenha papel primordial no controle do apetite, modulando fatores neurais e endócrinos, afetando o comportamento alimentar, pois recebe múltiplos sinais neuroendócrinos, além de ser acessível a fatores solúveis da circulação sangüínea periférica ${ }^{3}$.

Recentemente, Chaudhri et al. ${ }^{31}$ sugeriram que a OXM e o GLP-1, além de serem hormônios anorexígenos, agem via caminhos distintos, mas com semelhantes receptores. De acordo com Baynes et al. ${ }^{3}$ seria via receptor de GLP-1, pois o efeito da OXM pode ser bloqueado por um antagonista deste receptor, exenatida9 ${ }^{9-39}$.

A OXM age via ligação com os receptores de glucagon, GLP-1, GLP-2 os quais farmacologicamente são os únicos responsáveis pelo sítio de ligação ou recepção deste hormônio. No entanto, esses mecanismos ainda não estão totalmente esclarecidos ${ }^{32}$. Segundo Sowden et al..$^{33}$, a administração de OXM em camundongos com o receptor de GLP-1 bloqueado não promove redução da ingestão alimentar e não altera a temperatura corporal. Desse modo, as ações da OXM parecem ser dependentes dos receptores de GLP-1. 
Embora grande parte da OXM possua uma seqüência de aminoácidos similar ao glucagon, este peptídeo é ligado via receptor de glucagon nas membranas hepáticas com, aproximadamente, $2-10 \%$ de afinidade entre elas ${ }^{6,32}$. Assim, segundo Fehmann et al. ${ }^{34}$, o papel da OXM na homeostase energética também é mediado via receptor de GLP-1.

De acordo com Wynne et al. ${ }^{5}$, as áreas envolvidas na regulação do apetite são os núcleos arqueado, paraventricular, supra-óptico, trato solitário, o hipotálamo ventromedial e a área postrema, sendo que a ativação ou inibição da área dependerá de cada hormônio. Chaudhri et al. ${ }^{35}$ observaram que a administração intraperitoneal de OXM (900 e 5400 $\mathrm{nmol} / \mathrm{kg}$ ) resultou na diminuição da intensidade dos sinais, refletindo na redução da atividade neuronal, nos núcleos arqueado, paraventricular e supraóptico do hipotálamo. Por outro lado, a infusão de GPL-1 $(900 \mathrm{nmol} / \mathrm{kg}$ ) diminuiu somente a intensidade dos sinais enviados para o núcleo paraventricular e aumentou no ventromedial.

Recentemente, Chaudhri et al. ${ }^{31}$ também verificaram que a administração intraperitoneal de OXM (1400nmol/kg) promove alterações significativas na intensidade dos sinais nos núcleos arqueado, supraóptico e na área postrema, sem diferença significativa entre os camundongos alimentados ou em jejum. Já a administração do GLP-1 (900nmol/kg) promoveu alterações significantes na intensidade dos sinais no núcleo paraventricular, no hipotálamo ventromedial e na área postrema, independentemente do estado alimentar. Dessa forma, as pesquisas demonstram que a oxintomodulina e os hormônios intestinais (GLP-1) agem via distintos caminhos, apesar de compartilharem o mesmo receptor. Como citado anteriormente, existem evidências de que o receptor do GLP-1 medeia a ação da OXM, podendo a exenatida ${ }_{9-39}$ inibir os efeitos anoréticos da $\mathrm{OXM}^{36}$. Embora a exenatida ${ }_{9-39}$ possa bloquear o apetite, quando se administra OXM e GLP-1 via central, o antagonista, uma vez infundido dentro do núcleo arqueado, é responsável por abolir os efeitos do uso periférico de OXM, mas não os do GLP-137.

\section{Relação entre oxintomodulina, ingestão, gasto energético e composição corporal}

Atualmente, sabe-se que a OXM age aumentando o gasto energético e reduzindo o consumo alimentar. Além disso, ela tem função de sinalizar o cérebro que já existe suprimento de energia suficiente para as demandas fisiológicas $^{24,35,38}$.

Diante do citado acima, os estudos sobre o efeito anorético da OXM em animais sugerem ação central e periférica. Para entender o papel da OXM, bem como de outros hormônios intestinais (GLP-1 e PYY) no emagrecimento, há necessidade de conhecer duas populações de neurônios presentes no hipotálamo, mais especificamente no núcleo arqueado. A população denominada AgRP/NPY sintetiza neuropeptídeos orexígenos como o neuropeptídeo Y (NPY) e agouti (AgRP). Enquanto que a população POMC/CART, localizada na porção lateral do arqueado, sintetiza neuropeptídeos anorexígenos, que são a pró-opiomelanocortina (POMC) e seus derivados, como o hormônio alfa-melanócito estimulador $(\alpha-M S H)$ e o transcrito, relacionado à cocaína e à anfetamina (CART) $)^{23,30}$.

Resumidamente, sabe-se que a OXM, juntamente com outros peptídeos intestinais (GLP-1 e PYY), apresenta diversas funções, quais sejam: $1^{\circ}$ : age no núcleo arqueado, inibindo o AgRP/NPY (neurônios orexígenos); $2^{\circ}$ : atua via nervo vago, enviando sinais eferentes ao núcleo do trato solitário e hipotálamo estimulando a população de neurônios POMC/CART; $3^{\circ}$ : a OXM também pode atuar diretamente no hipotálamo inibindo a ingestão alimentar; $4^{\circ}$ após a ativação dos neurônios anorexígenos (POMC, CART e $\alpha-\mathrm{MSH})$, estes se ligam aos receptores de melanocortina 3 e 4 (MC 3 e MC 4), aumentando o gasto energético e diminuindo o consumo alimentar; $5^{\circ}$ contrapondo os efeitos benéficos da OXM, mutações podem ocorrer com o gene que expressa a OXM, e inibir os receptores MC 3 e MC 4, levando à obesidade (Figura 1) 3,11,20,37,39,40. 


\section{Estudos experimentais e clínicos que utilizaram a oxintomodulina como agente terapêutico na obesidade}

Os estudos demonstram que as administrações intraperitoneal e intracerebroventricular de OXM inibem a ingestão alimentar em roedores ${ }^{37}$, sendo o efeito da OXM anulado quando há bloqueio dos receptores de GLP-13.

Dakin et al. ${ }^{41}$, em pesquisa experimental, mostraram que as administrações intracerebroventricular de OXM promovem forte inibição da ingestão alimentar. Logo após este experimento, os mesmos pesquisadores observaram que a OXM também promove redução no ganho de peso e na adiposidade corporal ${ }^{42}$. Posteriormente, Dakin et al..$^{43}$ observaram que ratos tratados com OXM perdem mais peso do que os do grupo controle, consumindo a mesma quantidade energética.
Além disso, a administração periférica de OXM diminuiu o consumo de alimentos, principalmente durante a noite. Dessa forma, os autores sugeriram que este efeito anorético da OXM pode ser mediado por aumento na estimulação do $\alpha-\mathrm{MSH}^{43}$. Além disso, Sowden et al. ${ }^{33}$ demonstraram que a administração intraperitoneal de OXM em camundongos reduziu a ingestão alimentar de 60 a 90 minutos após a infusão, quando comparada à ao controle.

Atualmente, em quatro estudos realizados com camundongos submetidos à infusão de OXM via intraperitoneal observaram-se redução da ingestão alimentar9-11,44. O mesmo foi encontrado em frangos que receberam OXM via intracerebroventricular ${ }^{45}$.

Parlevliet et al. ${ }^{40}$, ao avaliarem os efeitos da administração aguda de OXM via intraperitoneal sobre o metabolismo da glicose de camun-

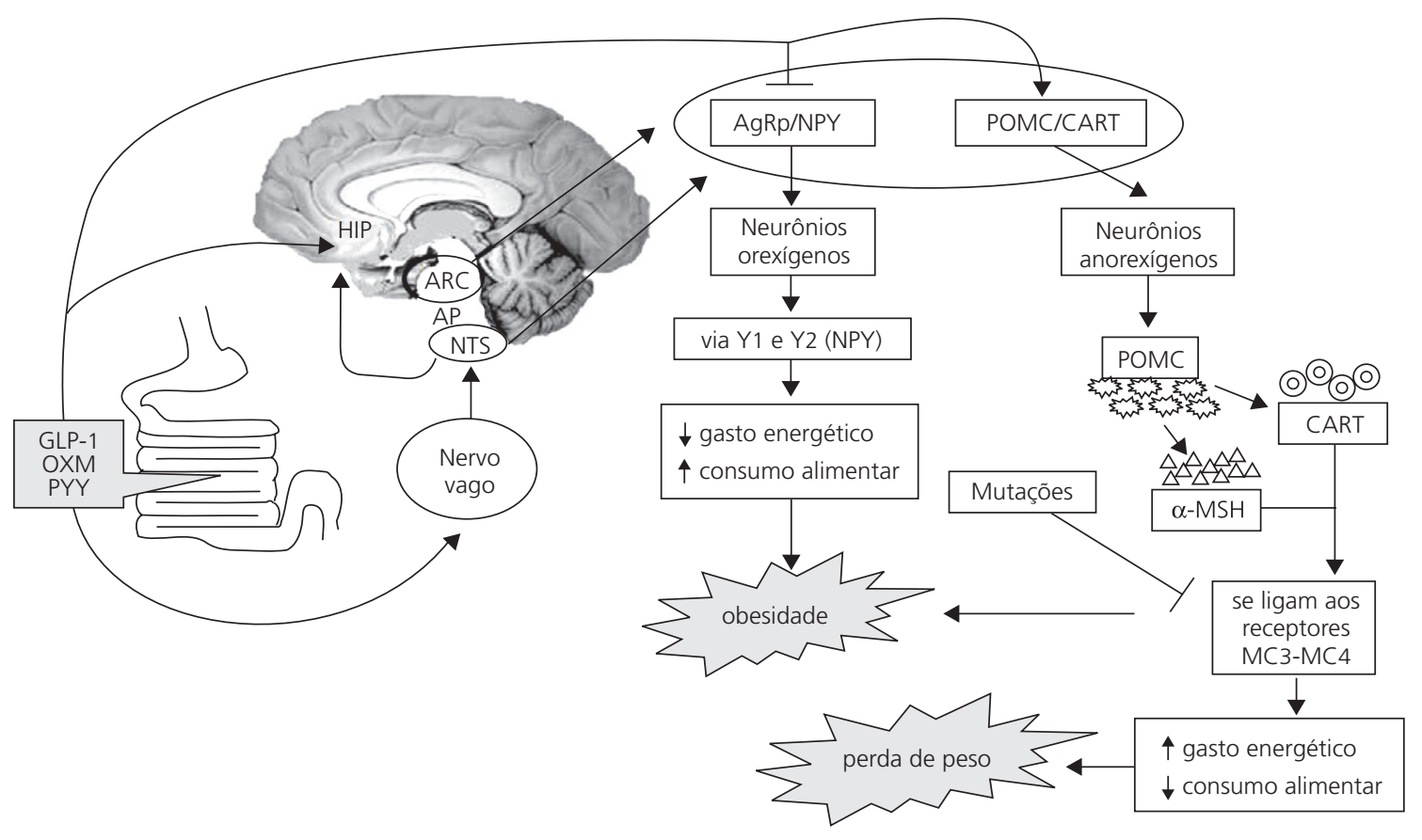

Figura 1. Representação esquemática das ações dos peptídeos intestinais na obesidade.

Nota: GLP-1: Glucagon like peptídeo 1; OXM: oxintomodulina; PYY: peptídeo YY; ARC: núcleo arqueado; AP: área postrema; NTS: núcleo do trato solitário; AgRP: peptídeo agouti; NPY: neuropeptídeo Y; POMC: pró-opiomelanocortina; CART: transcrito relacionado à cocaína e à anfetamina; $\alpha$-MSH: hormônio alfa-melanócito estimulador; MC3 receptor de melanocortina 3; MC4: receptor de melanocortina 4; Y1: neuropeptídeo Y da família do receptor subtipo 1; Y2: neuropeptídeo Y da família do receptor subtipo 2; HIP: hipotálamo. 
dongos alimentados com dieta induzida para obesidade (44\% do total energético como gordura bovina), mostraram que a OXM melhora a intolerância à glicose. No entanto, não foram expostos os dados de consumo alimentar, o que poderia ser considerada uma falha do estudo.

Cohen et al. ${ }^{7}$ relatam que parte do efeito anorexígeno da OXM pode ser via supressão das concentrações plasmáticas de grelina. Vale ressaltar que este estudo foi realizado em humanos, e que a infusão foi intravenosa. Logo, ao inibir a grelina ocorre também diminuição na estimulação do apetite, da secreção gástrica e do aumento da secreção de insulina, diminuindo a glicemia plasmática. Além disso, adultos caucasianos, índios Pima $^{46}$ e crianças obesas ${ }^{47}$ apresentam baixas concentrações séricas de grelina. A infusão de OXM diminui o esvaziamento gástrico, quando o estômago contém 3/4 de alimento. Subseqüentemente, a quantidade de alimentos liberados no jejuno torna-se baixa, podendo haver redução da ingestão alimentar e do peso corporal. Dessa forma, vários estudos demonstram que a OXM pode reduzir a secreção digestiva do estômago e evitar o esvaziamento gástrico, promovendo maior saciedade ${ }^{7,48}$.

O mesmo estudo acima observou que a administração intravenosa de OXM reduz em 19\% a ingestão energética, em pacientes eutróficos ${ }^{7}$. Em indivíduos com sobrepeso e obesos, após quatro semanas de tratamento, foi observada redução de $25 \%$ na ingestão energética e de 2,3kg (2,4\%) no peso corporal ${ }^{14}$. Posteriormente, Wynne et al. ${ }^{49}$ demonstraram que a infusão de OXM por quatro dias aumenta significativamente o gasto energético em indivíduos com sobrepeso e em obesos.

Outros pesquisadores, como Lê Roux et al..$^{50}$, investigaram os efeitos da secreção dos hormônios intestinais na cirurgia bariátrica, e observaram uma resposta endócrina do intestino como responsável pelo controle glicêmico, redução do apetite e redução do peso corporal, a longo-prazo. Conforme o esperado, após a cirurgia bypass as concentrações de grelina apresentaram-se reduzidas, pois a maior parte do estômago que secreta grelina foi removida, levando à diminuição da estimulação do apetite ${ }^{51}$.

Vale ressaltar, também, que a cirurgia de bypass age diretamente diminuindo o apetite ${ }^{3}$. Além da diminuição nas concentrações de grelina, algumas investigações mostraram que a cirurgia tem efeitos significantes na liberação de outros peptídeos, como aumento da OXM, PYY e GLP-150, promovendo balanço energético negativo e diminuindo o peso corporal em obesos $23,38,49$.

O paradoxo de que os indivíduos obesos apresentam menores concentrações séricas de grelina e, após a cirurgia bariátrica esses níveis também são reduzidos, é extremamente complexo. Segundo alguns estudos $47,52,53$, esse paradoxo pode estar envolvido com inúmeros motivos: $1^{\circ}$ : o fato de as concentrações de grelina serem inversamente relacionadas com o índice de massa corporal; $2^{\circ}$ : por a perda de peso, nem sempre, ser paralela aos altos níveis de grelina; $3^{\circ}$ : as concentrações de grelina podem estar maiores antes das refeições em indivíduos com sobrepeso (não obesos). No entanto, os estudos nem sempre são concordantes, pois o momento da dosagem do hormônio difere muito entre eles; $4^{\circ}$ : os locais de produção da grelina são diversos (estômago, intestino, placenta, pituitária e, até, no hipotálamo), portanto alguns órgãos podem agir diferentemente, levando menores ou maiores quantidades de grelina para a circulação; $5^{\circ}$ : a quantidade de grelina circulante pode ser menos regulada em indivíduos obesos, quando comparada com a de eutróficos. Além disso, esta menor regulação pode ser conseqüência de elevados níveis de insulina e leptina, pois estes hormônios anorexígenos, em grandes quantidades, podem diminuir as concentrações de grelina.

Nas Tabelas 1 e 2 podem ser observados os estudos experimentais e clínicos, que utilizaram a OXM como agente anti-obesidade. 
Tabela 1. Relação de estudos sobre os efeitos da administração de oxintomodulina versus controle, encontrados em estudos experimentais.

\begin{tabular}{|c|c|c|c|c|c|c|}
\hline Autores & Amostra & $\mathrm{N}^{\circ}$ & Duração & Administração & Dose & $\begin{array}{c}\text { Resultados: } \\
\text { oxintomodulina vs. controle* }\end{array}$ \\
\hline \multirow[t]{2}{*}{ Dakin et al. ${ }^{41}$} & \multirow[t]{2}{*}{ Ratos Wistar } & \multirow[t]{2}{*}{24} & \multirow[t]{2}{*}{24 horas } & \multirow[t]{2}{*}{ ICV } & 0,3 e $1,0 \mathrm{nmol} / \mathrm{kg}$ & $\downarrow$ IA somente até as oito primeiras horas \\
\hline & & & & & 3,0 e $10 \mathrm{nmol} / \mathrm{kg}$ & $\downarrow$ IA somente até as oito primeiras horas \\
\hline Dakin et al. ${ }^{42}$ & Ratos Wistar & 45 & $\begin{array}{l}7 \text { dias } \\
2 \times / d i a\end{array}$ & ICV & $1,0 \mathrm{nmol} / \mathrm{kg}$ & $\begin{array}{l}\downarrow \mid \mathrm{A} \text {, peso corporal e tecido adiposo } \\
\text { branco e marrom }\end{array}$ \\
\hline Dakin et al. ${ }^{43}$ & Ratos Wistar & $\begin{array}{l}12 \\
12 \\
15 \\
15\end{array}$ & $\begin{array}{l}24 \text { horas } \\
1 \text { hora } \\
7 \text { dias } \\
24 \text { horas }\end{array}$ & $\begin{array}{l}\text { Periférica } \\
\text { Periférica } \\
\text { Periférica } \\
\text { Periférica }\end{array}$ & $\begin{array}{c}3,0 \text { e } 10 \mathrm{nmolkg} \\
30 \mathrm{nmol} / \mathrm{kg} \\
50 \mathrm{nmol} / \mathrm{kg} \\
100 \mathrm{nmol} / \mathrm{kg}\end{array}$ & $\begin{array}{l}\text { Não alterou a IA } \\
\downarrow \text { IA } \\
\downarrow \mid A \text {, peso e adiposidade corporal } \\
\downarrow \mid A\end{array}$ \\
\hline Baggio et al. ${ }^{37}$ & Camundongo & $\begin{array}{l}4-7 \\
4-7 \\
5-8\end{array}$ & $\begin{array}{l}24 \text { horas } \\
24 \text { horas } \\
24 \text { horas }\end{array}$ & $\begin{array}{l}\text { ICV } \\
\text { ICV } \\
\text { ICV }\end{array}$ & $\begin{array}{c}1,0 \mu \mathrm{g} \\
5 \text { ou } 15 \mu \mathrm{g} \\
15 \text { ou } 100 \mu \mathrm{g}\end{array}$ & $\begin{array}{l}\text { Não alterou a IA } \\
\downarrow \text { IA até } 8 \text { horas após infusão de OXM } \\
\text { Não alterou a IA }\end{array}$ \\
\hline Sowden et al. ${ }^{33}$ & Camundongo & $\begin{array}{l}9 \\
6\end{array}$ & $\begin{array}{l}30 \text { minutos } \\
60 \text { minutos }\end{array}$ & $\begin{array}{l}\mathbb{P} \\
\mathbb{I P}\end{array}$ & $\begin{array}{l}15 \mu g \\
22 \mu g\end{array}$ & $\begin{array}{l}\downarrow \mid A \\
\downarrow \mid A\end{array}$ \\
\hline White et al. ${ }^{9}$ & Camundongo & 14 & 24 horas & IP & $6,2 \mathrm{mg} / \mathrm{kg}$ & $\downarrow$ IA somente na primeira hora \\
\hline Maida et al. ${ }^{44}$ & Camundongo & $3-4$ & 24 horas & IP & $250 \mu \mathrm{g}$ & $\begin{array}{l}\downarrow \text { IA somente até as duas primeiras } \\
\text { horas }\end{array}$ \\
\hline \multirow[t]{5}{*}{ Cline et al. ${ }^{45}$} & & & & ICV & $\begin{array}{l}0,67 ; 1,34 \mathrm{e} \\
2,68 \mathrm{nmol} / \mathrm{kg}\end{array}$ & Todas as doses reduziram a IA \\
\hline & & & & & $\begin{aligned} & 0,28 ; 5,65 \\
\text { e } & 11,3 \mathrm{nmol} / \mathrm{kg}\end{aligned}$ & Sem efeito \\
\hline & \multirow[t]{3}{*}{ Frango } & \multirow[t]{3}{*}{ SI } & \multirow[t]{3}{*}{180 minutos } & IP & $\begin{array}{l}0,68 ; 1,36 \mathrm{e} \\
2,71 \mathrm{nmol} / \mathrm{kg}\end{array}$ & Sem efeito \\
\hline & & & & & $\begin{aligned} & 0,11 ; 1,13 \\
\text { e } & 11,3 \mathrm{nmol} / \mathrm{kg}\end{aligned}$ & Sem efeito \\
\hline & & & & Veia braquial & $\begin{array}{l}0,32 ; 3,17 \mathrm{e} \\
31,7 \mathrm{nmol} / \mathrm{kg}\end{array}$ & Sem efeito \\
\hline Druce et al. ${ }^{10}$ & Camundongo & $8-10$ & 24 horas & IP & $\begin{array}{l}800 \mathrm{nmol} / \mathrm{kg} \\
1400,2200 \mathrm{e} \\
3800 \mathrm{nmol} / \mathrm{kg}\end{array}$ & $\begin{array}{l}\text { Não alterou a IA } \\
\downarrow \text { IA nas doses de } 1400 \mathrm{nmo} / \mathrm{kg} \text { e maiores }\end{array}$ \\
\hline Parkinson et al. ${ }^{11}$ & Camundongo & $8-12$ & 140 minutos & IP & $1400 \mathrm{nmol} / \mathrm{kg}$ & $\begin{array}{l}\downarrow \text { IA a partir dos } 55 \text { minutos até o final } \\
\text { (140 minutos) }\end{array}$ \\
\hline
\end{tabular}

* $p<0$,05. ICV: intracerebroventricular; IP: intraperitoneal; IA: ingestão alimentar; SI: sem informação; OXM: oxintomodulina.

\section{Efeitos adversos da administração de oxintomodulina}

Diferentemente dos atuais agentes químicos, que são usados indiscriminadamente, a administração dos hormônios intestinais teria maior vantagem em controlar o apetite. Quando utilizados diariamente apresentam baixos efeitos colaterais e menores índices de taquifilaxia. Todavia, seu uso contínuo seria necessário para a manutenção do peso, caso não ocorressem mudanças do estilo de vida ${ }^{54}$.

Em humanos, Wynne et al. ${ }^{14}$ administraram $400 \mathrm{nmol}$ de OXM por quatro semanas, três vezes ao dia e 30 minutos antes de cada refeição, e observaram que os pacientes apresentavam desconfortos gastrointestinais. No total, $3 \%$ dos indivíduos relataram náusea quando administrada a OXM, comparados com 0,2\% 
734 | G.D. PIMENTEL et al.

Tabela 2. Relação de estudos clínicos sobre os efeitos da administração de oxintomodulina versus controle.

\begin{tabular}{|c|c|c|c|c|c|c|c|}
\hline Autores & Estudo & Amostra & $\mathrm{N}$ & Duração & Administração & Dose & $\begin{array}{c}\text { Resultados } \\
\text { oxintomodulina vs. controle* }\end{array}$ \\
\hline Cohen et al. ${ }^{7}$ & $\begin{array}{l}\text { R, DC, } \\
\mathrm{PC} \mathrm{e} \\
\mathrm{CO}\end{array}$ & $\mathrm{HE}$ & 13 & 24 horas & Intravenosa & $3 \mathrm{pmol} / \mathrm{kg} / \mathrm{min}$ & $\begin{array}{l}\text { Tempo 0: } \downarrow \text { IA em } 19,3 \% \\
\text { Tempo } 12 \text { horas: } \downarrow \text { IA em 11,3\% } \\
\text { Tempo } 24 \text { horas: sem diferença }\end{array}$ \\
\hline Wynne et al. ${ }^{14}$ & $\begin{array}{l}\mathrm{R}, \mathrm{DC} \mathrm{e} \\
\mathrm{PC}\end{array}$ & $\mathrm{HS} ; \mathrm{HO}$ & 26 & $\begin{array}{l}4 \text { semanas } \\
(3 \times / d i a)\end{array}$ & $\begin{array}{l}\text { Subcutânea } \\
\text { (pré-prandial) }\end{array}$ & $400 \mathrm{nmol} / \mathrm{kg}$ & $\begin{array}{l}\text { Controle: } \downarrow \text { peso corporal em } 0,5 \% \text { (des- } \\
\text { vio-padrão - DP=0,6) }(p=0,012) \\
\text { OXM: } \downarrow \text { peso corporal em } 2,4 \%(p=0,01) \\
\text { e da IA em } 25 \% \text { no } 1^{\circ} \text { dia }(p=0,0007) \text { e } \\
\text { em } 35 \% \text { no } 29^{\circ} \text { dia }(p=0,002)\end{array}$ \\
\hline Wynne et al. ${ }^{51}$ & $\begin{array}{l}\text { R, DC, } \\
\text { PC e } \\
\text { CO }\end{array}$ & $\mathrm{HS} ; \mathrm{HO}$ & 15 & $\begin{array}{c}4 \text { dias } \\
(3 \times / d i a)\end{array}$ & $\begin{array}{l}\text { Subcutânea } \\
\text { (pré-prandial) }\end{array}$ & $400 \mathrm{nmol} / \mathrm{kg}$ & $\begin{array}{l}\downarrow \text { IA em } 17,3 \% \text { e peso corporal em 0,5\%. } \\
\uparrow \text { gasto energético total em 9,4\% } \\
\uparrow \text { nível de atividade física em 9,5\% }\end{array}$ \\
\hline
\end{tabular}

$\mathrm{n} *$ : ambos os sexos: ${ }^{* *} p<0,05$.

R: randomizado; C: controlado; DC: duplo-cego; CO: crossover; PC: placebo controlado; HE: humanos eutróficos; HS: humanos com sobrepeso; HO: humanos obesos; IA: ingestão alimentar; OXM: oxintomodulina; min: minutos.

nos indivíduos aos quais se administrou salina. Em relação à freqüência cardíaca, à pressão arterial e à palatabilidade, não foram encontradas alterações. Vale ressaltar que este foi o único estudo em humanos que encontrou efeitos adversos. No entanto, todos os sintomas foram auto-relatados, podendo ter havido envolvimento psicológico. Além disso, os sintomas são considerados mínimos e insignificantes. Os outros dois estudos em humanos não observaram efeitos colaterais ${ }^{7,49}$.

Igualmente em animais, apenas um estudo encontrou efeitos adversos. Sowden et al. ${ }^{33}$ observaram um aumento importante da freqüência cardíaca intrínseca em camundongos com o receptor de GLP-1 bloqueado, ou seja, este resultado sugere que o aumento na freqüência foi independente do receptor de GLP-1, podendo ser via receptor do glucagon ou algum receptor da OXM ainda não identificado.

Recentemente, quatro pesquisas em camundongos $\mathrm{s}^{9-11,44}$ e uma em frango ${ }^{45}$ não observaram efeitos adversos.

\section{PERSPECTIVAS FUTURAS}

Os esforços para desenvolver tratamento farmacológico contra o excesso de peso têm aumentado alarmantemente nas últimas décadas, estimulado pelo avanço nos índices de obesidade e o subseqüente reconhecimento como uma doença crônica ${ }^{1}$, além do interesse da indústria farmacêutica.

Atualmente, as terapias com drogas não são eficazes para evitar a epidemia da obesidade e, até o momento, o tratamento mais eficaz para obesos mórbido é a cirurgia bariátrica. Embora o papel fisiológico dos hormônios intestinais na homeostase energética possa ser difícil de comprovar, a administração exógena dos hormônios intestinais pode influenciar a ingestão alimentar em humanos ${ }^{38}$.

Na literatura, existem poucos estudos com humanos que mostram o efeito anorético da terapia com peptídeos intestinais. Por isso, mais estudos de longo prazo são necessários, para averiguar se a constância deste efeito é clinicamente útil ${ }^{3}$. Além disso, os estudos atuais não diferenciam quanto ao nível de atividade física e não detalham a ingestão alimentar dos participantes, a fim de evitar qualquer viés que possa interferir e mascarar os resultados. Para melhor interpretação dos resultados, os estudos deveriam, também, coletar e integrar dados referentes à farmacologia da OXM (dose, duração, relação dose-efeito) ${ }^{33}$. 


\section{CONSIDERAÇÕES FINAIS}

Conforme o já comentado, após a descoberta de alguns hormônios, abriram-se novos campos de estudo para o controle da ingestão alimentar e da obesidade, principalmente nas áreas de nutrição, fisiologia e metabolismo. Diante dos estudos aqui relatados, conclui-se que a oxintomodulina tem importante papel anorexígeno, com funções de reduzir a ingestão alimentar em $25 \%$ em humanos e em $20-60 \%$ em animais, além do peso e da adiposidade corporal. Para que essas funções tenham efeito, os estudos apontam que a OXM age via receptor do peptídeo semeIhante ao glucagon 1, ativando os neurônios anorexígenos (POMC/CART) e inibindo os orexígenos (AgRP/NPY). Além disso, a literatura mostra que, juntamente com a adoção de hábitos saudáveis e a mudança do estilo de vida, a oxintomodulina pode proporcionar menor avanço da obesidade.

\section{A GRADECIMENTOS}

À Juliane Costa Silva Zemdegs, pelo auxílio na elaboração da figura e das tabelas do manuscrito. Ao Conselho Nacional de Desenvolvimento Científico e Tecnológico, pela bolsa de mestrado concedida a Gustavo Duarte Pimentel, Universidade Federal de São Paulo.

\section{COLABORADORES}

G.D. PIMENTEL responsável pela idéia e pela condução da revisão bibliográfica pertinente, bem como pela redação do manuscrito. J.F. MOTA participou da revisão bibliográfica, da escolha dos manuscritos revisados e da redação do manuscrito. L.M. OYAMA participou da redação, da orientação e da revisão final do trabalho.

\section{REFERÊ N CIAS}

1. World Health Organization. Global strategy on diet, physical activity and health: obesity and overweight. Geneva. [cited 2007 Mar 4]. Available from:<http://www.who.int/ dietphysicalactivity/ publications/facts/obesity/en/>.
2. Instituto Brasileiro de Geografia e Estatística. Pesquisa de orçamento familiar (POF), 2002/2003. Rio de Janeiro. [acesso 2009 fev 2]. Disponível em: $<$ http://www.ibge.gov.br>.

3. Baynes KCR, Dhillo WS, Bloom SR. Regulation of food intake by gastrointestinal hormones. Curr Opin Gastroenterol. 2006; 22(6):626-31. doi: 10.1097/01.mog.0000245537.43142.63.

4. Halpern ZSC, Rodrigues MDB, Costa RF. Determinantes fisiológicos do controle de peso e apetite. Rev Psiq Clin. 2004; 31(4):150-3. doi: 10.1590/ S0101-60832004000400002.

5. Wynne K, Stanley S, Bloom S. The gut and regulation of body weight. J Clin Endocrinol Metab. 2004; 89(6):2576-82. doi: 10.1210/jc.2004-0189.

6. Bataille D, Gespach C, Tatemoto K, Marie JC, Coudry AM, Rosselin G, et al. Bioactive enteroglucagon (oxyntomodulin): present knowledge on its chemical structure and its biological activities. Peptides. 1981; 2(Suppl 2): 41-4.

7. Cohen MA, Ellis SM, Lê Roux CW, Batterham RL, Park A, Patterson $M$, et al. Oxyntomudulin suppesses appetite and reduces food intake in humans. J Clin Endocrinol Metab. 2003; 88(10): 4696-701. doi: 10.1210/jc.2003-030421.

8. Pimentel GD, Mota JF, Guimaraes MP, Fioravante MA. A oxintomodulina como uma nova terapia anti-obesidade [Abstract]. Rev Bras Med. 2007; 64(Supl. 1):131.

9. White NE, Dhillo WS, Liu YL, Small CJ, Kennett GA, Gardiner JV, et al. Co-administration of SR141716 with peptide YY3-36 or oxyntomodulin has additive effects on food intake in mice. Diabetes Obes Metabol. 2008; 10(2):167-70. doi: 10.1111/ j.1463-1326.2007.00807.x.

10. Druce MR, Minnion JS, Field BC, Patel SR, Cuenco-Shilito J, Tilby $M$, et al. Investigation of structureactivity relationships of oxyntomodulin using oxyntomodulin analogues. Endocrinology. 2009; 150(4):1712-22. doi: 10.1210/en.2008-0828.

11. Parkinson JRC, Chaudhri OB, Kuo YT, Field BCT, Herlihy AH, Dhillo WS. Differential patterns of neuronal activation in the brainstem an hypothalamus following peripheral injection of GLP-1, oxyntomodulin and lithium chloride in mice detected by manganese-enhanced magnetic resonance imaging (MEMRI). Neuroimage. 2009; 44(3):1022-31. doi: 10.1016/j.neuroimage.2008. 09.047.

12. Tatemoto K, Mutt V. Isolation of two novel candidate hormones using a chemical method for finding naturally occurring polypeptides. Nature. 1980; 285(5764):417-8. doi: 10.1038/285417a0. 
13. Blache P, Kevran A, Bataille D. Oxyntomodulin and glicentin: brain gut peptides in the rat. Endocrinology. 1988; 123(6):2782-7. doi: 10.1210/endo-123-6-2782.

14. Wynne K, Park AJ, Small CJ, Patterson M, Ellis SM, Murphy KG, et al. Subcutaneous oxyntomodolin reduces body weight in overweight and obese subjects: a double-blind, randomized, controlled trial. Diabetes. 2005; 54(8):2390-5. doi: 10.2337/ diabetes.54.8.2390.

15. Baldissera FG, Holst JJ. Glucagon-related peptides in the human gastrointestinal mucosa. Diabetologia. 1984; 26(3):223-8. doi: 10.1007/BF00 252412.

16. Le Quellec A, Kervran A, Blache P, Ciurana AJ, Bataille D. Oxyntomodulin-like immunoreactivity: diurnal profile of a new potential enterogastrone. J Clin Endocrinol Metab. 1992; 74(6):1405-9.

17. Holst JJ. Enteroglucagon. Ann Rev Physiol. 1997; 59:257-71. doi: 0066-4278/97/0315-0257 $\$ 08.00$.

18. Blázquez E, Álvarez E, Albusac JMR, Roncero I, Velázquez E. Papel de los péptidos semejantes al glucagón sobre el control de la ingesta de alimentos. Rev Esp Obes. 2004; 2(2):99-112.

19. Stepanenko VN, Esipov RS, Gurevich Al, Chupova LA, Miroshnikov Al. Recombinant oxyntomodulin. Rus J Bioorg Chem. 2007; 33(2):227-32. doi: 10.1134/S1068162007020045.

20. Druce MR, Bloom SR. Oxyntomodulin: a novel potential treatment for obesity. Treat Endocrinol. 2006; 5(5):265-72.

21. Anini Y, Fu-Cheng X, Cuber JC, Kervran A, Chariot J, Rozé C. Comparasion of the postprandial release of peptide $Y Y$ and proglucagon-derived peptides in the rat. Pfugers Arch. 1999; 438(3):299-306. doi: $10.1007 / s 004240050913$

22. Schjoldager B, Mortensen PE, Myhre J, Christiansen J, Holst JJ. Oxyntomodulin from distal gut: role in regulation of gastric and pancreatic functions. Dig Dis Sci. 1989; 34(9):1411-9.

23. Sarson DL, Scopinaro N, Bloom SR. Gut hormone changes after jejunoileal (JIB) or biliopancreatic (BPB) bypass surgery for morbid obesity. Int J Obes. 1981; 5(5):471-80.

24. Wynne K, Bloom SR. The role of oxyntomodulin and peptide tyrosine-tyrosine (PYY) in appetite control. Nature. 2006; 2(11):612-20. doi: 10.1038/ ncpendmet0318.

25. Besterman HS, Cook GC, Sarson DL, Christofides ND, Bryant MG, Gregor M, et al. Gut hormones in tropical malabsorption. Br Med J. 1979; 2(6200): 1252-5
26. Holst JJ, Sorensen TI, Andersen AN, Stadil F, Andersen B, Lauritsen KB, et al. Plasma enteroglucagon after jejunoileal bypass with 3:1 or 1:3 jejunoileal ratio. Scand J Gastroenterol. 1979; 14(2):205-7.

27. Verdich C, Toubro S, Buemann B, Madsen JL, Holst JJ, Astrup A. The role of postprandial releases of insulin and incretin hormones in meal-induced satiety-effect of obesity and weight reduction. Inter J Obes Relat Metab Disord. 2001; 25(8):1206-14.

28. Guido R, Leiter AB, Kopin AS, Bordi C, Solcia E. The "normal" endocrine cell of the Gut: changing concepts and new evidences. Ann N Y Acad Sci. 2004; 1014(1):1-12. doi: 10.1196 annals.1294.001.

29. Martins MN, Telles MM, Zemdegs JC, Andrade IS, Ribeiro EB, Miranda A. Evaluation of new leptin fragments on food intake and body weight of normal rats. Regul Pept. 2008; 153(1-3):77-82. doi: 10.1016/j.regpep.2008.11.013.

30. Sainsbury A, Cooney GJ, Herzog H. Hypothalamic regulation of energy homeostasis. Best Pract Res Clin Endocrinol Metab. 2002; 16(4):623-37. doi: 10.1053/beem.2002.0230.

31. Chaudhri OB, Parkinson JRC, Herlihy AH, Salem V, Kuo YT, Bell JD, et al. Manganese-enchanced MRI demonstrates that oxyntomodulin and GLP-1 affect neuronal activity in distinct regions of the brain. Endocrine Abstracts. 2007; 13:OC27.

32. Baldissera FG, Holst JJ, Knuhtsen S, Hilsted L, Nielsen OV. Oxyntomodulin (glicentin-(33-69)): pharmacokinetics, binding to liver cell membranes, effects on isolated perfused pig pancreas, and secretion from isolated perfused lower small intestine of pigs. Regul Pept. 1988; 21(1-2):15166. doi: 10.1016/0167-0115(88)90099-7.

33. Sowden GL, Drucker DJ, Weinshenker D, Swoap SJ. Oxyntomodulin increases intrinsic heart rate in mice independent of the glucagon-like peptide-1 receptor. Am J Physiol Regul Integr Comp Physiol. 2007; 292(2):R962-R70. doi: 10.1152/ajpregu. 00405.2006.

34. Fehmann HC, Jiang J, Schweinfurth J, Wheeler MB, Boyd $A E$, Goke B. Stable expression of the rat GLP-I receptor in $\mathrm{CHO}$ cells: activation and binding characteristics utilizing GLP-I (7-36)-amide, oxyntomodulin, exendin-4, and exendin (9-39). Peptides. 1994; 15(3):453-6.

35. Chaudhri OB, Parkinson JRC, Kuo YT, Druce MR, Herlihy AH, Bell JD, et al. Differential hypothalamic neuronal activation following peripheral injection of GLP-1 and oxyntomodulin in mice detected by manganese-enhanced magnetic resonance imaging. Biochem Biophys Res Commun. 2006; 350(2):298-306. doi:10.1016/j.bbrc.2006.09.033. 
36. Schepp W, Dehne K, Riedel T, Schmidtler J, Schaffer K, Classen M. Oxyntomodulin: a CAMP-dependent stimulus of rat parietal cell function via the receptor for glucagon-like peptide 1 (7-36) NH2. Digestion. 1996; 57(6):398-405. doi: 10.1159/000201367.

37. Baggio LL, Huang Q, Brown TJ, Drucker DJ. Oxyntomodulin and glucagon-like peptide-1 differentially regulate murine food intake and energy expenditure. Gastroenterology. 2004; 127(2):546-58.doi:10.1053/j.gastro.2004.04. 063.

38. Murphy KG, Bloom SR. Gut hormones and the regulation of energy homeostasis. Nature. 2006; 444(7121):854-9. doi: 10.1038/nature05484.

39. Druce M, Ghatei M. Oxyntomodulin. Curr Opin Endrocrinol Diabetes. 2006; 13(1):49-55.

40. Parlevliet ED, Heijboer AC, Schröder-van der Elst JP, Havekes LM, Romijn JÁ, Pijl H, et al. Oxyntomodulin ameliorates glucose intolerance in mice fed a high-fat diet. Am J Physiol Endocrinol Metab. 2008; 294(1):E142-7. doi: 10.1152/ajpendo.00576. 2007.

41. Dakin CL, Gunn I, Small CJ, Edwards CM, Hay DL, Smith DM, et al. Oxyntomodulin inhibits food intake in the rat. Endocrinology. 2001; 142(10): 4244-50.

42. Dakin CL, Small CJ, Park AJ, Seth A, Ghatei MA, Bloom SR. Repeated ICV administration of oxyntomodulin causes a greater reduction in body weight gain than in pair-fed rats. Am J Physiol Endocrinol Metab. 2002; 283(6):E1173-77. doi: 10.1152/ajpendo.00233.2002.

43. Dakin CL, Small CJ, Batterham RL, Neary NM, Cohen MA, Patterson M, et al. Peripheral oxyntomodulin reduces food intake and body weight gain in rats. Endocrinology. 2004; 145(6):2687-95. doi: 10.1210/en.2003-1338.

44. Maida A, Lovshin JA, Baggio LL, Drucker DJ. The glucagon-like peptide-1 receptor agonist oxyntomodulin enhances $\beta$-cell function but does not inhibit gastric emptying in mice. Endocrinology. 2008; 149(11):5670-8. doi: 10.1210/en.2008-0336.

45. Cline MA, Bowden CN, Nandar W, Rogers JO. Central oxyntomodulin causes anorexigenic effects associated with the hypothalamus and alimentary canal in chicks (Gallus gallus). Comp Biochem Physiol A Mol Integr Physiol. 2008; 149(4):405-10. doi: 10.1016/j.cbpa.2008.01.038.
46. Nassar MF, Gomaa SM, El-Batrawy SR. Low ghrelin level affects biomarkers in childhood obesity. Nutr Res. 2007; 27(10):605-11. doi: 10.1016/j.nutres. 2007.06.014.

47. Dâmaso AR, Tock L, Tufik S, Prado WL, Stella SG, Fisberg $\mathrm{M}$, et al. Tratamiento multidisciplinar reduce el tejido adiposo visceral, leptina, grelina y la prevalencia de esteatosis hepática no alcohólica (NAFLD) en adolescentes obesos. Rev Bras Med Esp. 2006; 12(5):263-7. doi: 10.1590/\$1517-8692 2006000500008.

48. Pellissier S, Sasaki K, Le-Nguyen D, Bataille D, Jarrousse C. Oxyntomodulin and glicentin are potent inhibitors of the fed motility pattern in small intestine. Neurogastroenterol Motil. 2004; 16(4):455-63. doi: 10.1111/j.1365-2982.2004. 00528.x.

49. Wynne K, Park AJ, Small CJ, Meeran K, Ghatei MA, Frost GS, et al. Oxyntomodulin increases energy expenditure in addition to decresing energy intake in overweight and obese humans a randomised controlled trial. Int J Obes. 2006; 30(12):1729-36. doi: 10.1038/sj.ijo.0803344.

50. Lê Roux CW, Aylwin SJ, Batterham RL, Borg CM, Coyle F, Prasad V, et al. Gut hormone profiles following bariatric surgery favor an anorectic state, facilitate weight loss, and improve metabolic parameters. Ann Surg. 2006; 243(1):108-14. doi: 10.1097/01.sla.0000183349.16877.84.

51. Hanada T, Toshinai K, Date Y, Kajimura N, Tsukada $T$, Hayashi $Y$, et al. Upregulation of ghrelin expression in cachectic nude micebearing human melanoma cells. Metabolism. 2004; 53(1):84-8. doi: 10.1016/j.metabol.2003.06.004.

52. Lindeman J, Pijl H, van Dielen F, Lentjes E, van Leuven C, Kooistra T. Ghrelin and the hyposomatotropism of obesity. Obes Res. 2002; 10(11):1161-6. doi: 10.1038/oby.2002.157

53. Tschöp M, Weyer C, Tataranni PA, Devanarayan V, Ravussin E, Heiman ML. Circulating ghrelin levels are decreased in human obesity. Diabetes. 2001; 50(4):707-9. doi: 10.2337/diabetes.50.4.707.

54. Murphy KG, Bloom SR. Gut hormones in the control of appetite. Exp Physiol. 2004; 89(5): 507-16. doi: 10.1113/expphysiol.2004.027789.

Recebido em: 15/8/2007

Versão final reapresentada em: 12/3/2009 Aprovado em: 6/7/2009 